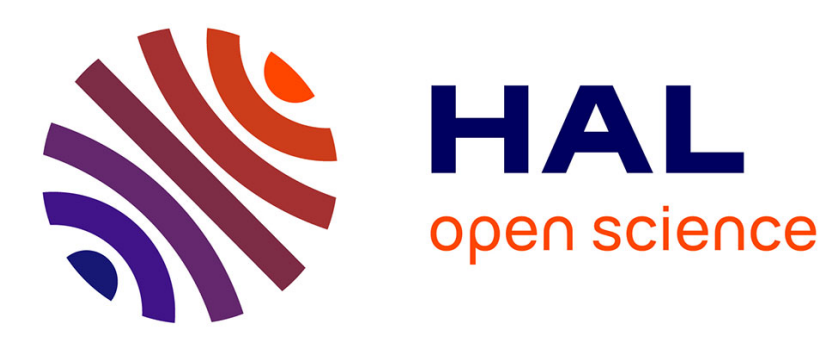

\title{
High blood pressure was associated with cognitive function in middle-age in the Whitehall II study.
}

Archana Singh-Manoux, Michael Marmot

\section{To cite this version:}

Archana Singh-Manoux, Michael Marmot. High blood pressure was associated with cognitive function in middle-age in the Whitehall II study.. Journal of Clinical Epidemiology, 2005, 58 (12), pp.1308-15. 10.1016/j.jclinepi.2005.03.016 . inserm-01155147

\section{HAL Id: inserm-01155147 https://www.hal.inserm.fr/inserm-01155147}

Submitted on 26 May 2015

HAL is a multi-disciplinary open access archive for the deposit and dissemination of scientific research documents, whether they are published or not. The documents may come from teaching and research institutions in France or abroad, or from public or private research centers.
L'archive ouverte pluridisciplinaire HAL, est destinée au dépôt et à la diffusion de documents scientifiques de niveau recherche, publiés ou non, émanant des établissements d'enseignement et de recherche français ou étrangers, des laboratoires publics ou privés. 
High blood pressure is associated with cognitive function in middle-age in the Whitehall II study.

Archana Singh-Manoux ${ }^{1,2} *$

Michael Marmot ${ }^{2}$

1*INSERM, Unit 687

HNSM, 14 rue du Val d'Osne

94415 Saint-Maurice Cedex, France

${ }^{2}$ Department of Epidemiology and Public Health

University College London

1-19 Torrington Place

London WC1E 6BT, U. K.

*Corresponding author \& address

Email: A.Singh-Manoux@ucl.ac.uk

Email: Archana.Singh-Manoux@st-maurice.inserm.fr

Tel : 33-(0)1- 45183863

Fax : 33-(0)1- 45183889

Word count: Abstract $=191 ;$ Text $=2,846$ 


\begin{abstract}
Background \& Objectives: Research shows elevated levels of blood pressure in midlife to be linked to impaired cognitive performance in old age. However, it remains unclear if this association extends to younger age groups. The objective of this study was to examine the association between hypertension and a range of cognitive abilities in middle aged men and women.
\end{abstract}

Methods: Data are from the Whitehall II study. Measures of blood pressure were obtained at baseline (1985-1988) and two subsequent phases of data collection (1991-1994 and 1997-1999). Cognitive function (memory test, AH 4-I, Mill-Hill, phonemic and semantic fluency) was assessed (1997-1999) when participants $(\mathrm{N}=5838)$ were aged 46-68 years old.

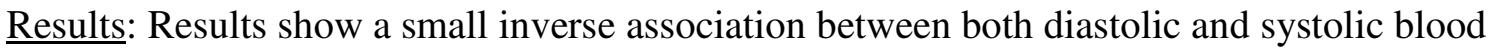
pressure and cognitive performance, independent of age, education, employment grade, smoking status, alcohol consumption, use of antihypertensive medication, diagnoses of diabetes and cardiovascular disease. Similar associations were seen with prospective and cross-sectional analyses. The effect of hypertension was stronger in women, and stronger for cognitive measures assessing executive function.

Conclusion: Expanding on previous studies on older participants, the present study reports a small, but significant association between hypertension and poor cognitive performance in middle-aged men and women.

Keywords: Blood pressure, hypertension, cognition, memory, middle age, verbal fluency.

Running title: Hypertension and cognition in midlife 
Hypertension has been widely linked to poor performance on neuropsychological tests (111). More specifically, research shows hypertension in midlife to be related to cognitive impairment in old age. Furthermore, it has been suggested that the link between hypertension and cognitive impairment develops before the onset of clinical symptoms of dementia; changes indicative of dementia were observed in brains of non-demented, middle-aged hypertensives (12). The implication is that healthy middle aged hypertensives may already have subtle neuropsychological deficits.

In this study, we examine this association in middle aged individuals using a battery of cognitive tests in order to allow an assessment of subtle cognitive deficits. The advantage of using standard cognitive tests rather than a specific test used to screen for dementia (e.g. the Mini Mental State Examination) is that it is less subject to ceiling effects, particularly in non-elderly populations. The disadvantage is the lack of standard criteria to judge poor cognitive performance and assign it clinical significance. However, recent attempts to identify poor performance as that being in the worst quintile (13), or below 1.5 standard deviation of the mean (14) provide appealing solutions to the problem. We also examine whether cross-sectional and prospective associations (mean follow up 11years) differ from each other, and whether systolic and diastolic blood pressure (SBP \& DBP) have similar relationships with cognition in midlife.

\section{METHODS}

\section{Study population}

The Whitehall II study was established in 1985 as a longitudinal study to examine the socioeconomic gradient in health and disease among 10,308 civil servants $(6,895$ men and 3,413 women). Full details of the cohort and its follow up have been published elsewhere (15) All civil servants aged 35-55 years in 20 London based departments were invited to participate by letter. 
In total, $73 \%$ of those invited agreed to take part in Phase 1. Baseline examination (Phase 1) took place during 1985-1988, and involved a clinical examination and a self-administered questionnaire containing sections on demographic characteristics, health, lifestyle factors, work characteristics, social support and life events. Clinical examination included measures of blood pressure, anthropometry, biochemical measurements, neuroendocrine function, and sub-clinical markers of cardiovascular disease. Subsequent phases of data collection have alternated between postal questionnaire alone (Phases 2, 4 and 6) and postal questionnaire accompanied by a clinical examination (Phases 1, 3 and 5). Since baseline five phases of data collection rounds have been completed, with the most recent phase of data collection (Phase 6) completed in 2001. The University College London ethics committee approved the study.

\section{Blood pressure}

Blood pressure was measured at Phases 1 (baseline, 1985-1988), 3 (1991-1994), and 5 (1997-1999). On each occasion blood pressure was measured twice in the sitting position after 5 minutes rest with the Hawksley random-zero sphygmomanometer. The average of these two was taken to be the measured blood pressure. In keeping with the research in this field the following categories were created for SBP: low $(<120 \mathrm{~mm} \mathrm{Hg})$, medium $(120-139 \mathrm{mmHg})$, and high $(\geq$ $140 \mathrm{~mm} \mathrm{Hg})(7,21)$. These are also the risk categories defined by the Joint National Committee's report (16) which were also used to categorize DBP as low (<80 mm Hg), medium (80-89 $\mathrm{mmHg})$, and high ( $\geq 90 \mathrm{~mm} \mathrm{Hg})$.

\section{Tests of cognitive function}

The cognitive test battery consisted of five standard tasks chosen to comprehensively evaluate cognitive functioning in middle-aged adults. High scores on all tests denote better performance. 
The first was a 20-word free-recall test of short-term verbal memory. Participants were presented with a list of 20 one-or two-syllable words at 2-second intervals and were then asked to recall in writing as many of the words as they could, in any order; they had 2 minutes to do so. The AH-4 I (17) is composed of a series of 65 verbal and mathematical reasoning items of increasing difficulty. This test of inductive reasoning measures the ability to identify patterns and infer principles and rules. Participants had 10 minutes to complete this section. The Mill Hill vocabulary test (18) assesses knowledge of verbal meaning and encompasses the ability to recognize and comprehend words. We used this test in its multiple format, which consists of a list of 33 stimulus words ordered by increasing difficulty and six response choices. Finally, we used two measures of verbal fluency: phonemic and semantic (19). Phonemic fluency was assessed via "s" words and semantic fluency via "animal" words. Subjects were asked to recall in writing as many words beginning with "s" and as many animal names as they could. One minute was allowed for each test of fluency.

\section{Confounders}

Physician diagnosed self-reported stroke cases $(\mathrm{N}=69)$ were excluded from analysis $(2,11,20-22)$. Self reported dementia using the ICD-9 to recode a question on long-standing illness, asked as part of the Phase 5 questionnaire, revealed no cases of dementia.

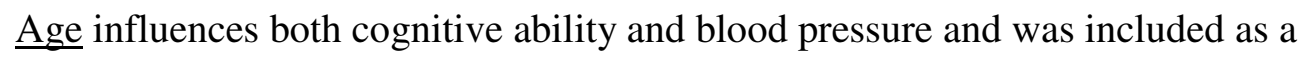
confounder in the analysis.

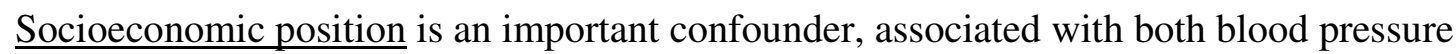
and cognitive ability $(2,20,22,23)$. In this study socioeconomic position was assessed via employment grade of participants, ranging from 1 to 6 , with grade 1 representing the highest 
level and grade 6 the lowest. People in different grades differ with respect to salary, social status and level of responsibility.

Education was measured as the highest level of education achieved, with the respondent choosing one of 11 categories in the questionnaire. This was regrouped into five standard hierarchic levels: (1) no formal education, (2) lower secondary education, (3) higher secondary education, (4) university degree, (5) higher university degree.

Both smoking $(2,20)$ and alcohol $(2,22,23)$ are regarded as confounders and were controlled for in the analysis.

Use of antihypertensive medication was adjusted for in the analyses.

Cardiovascular disease (CVD) (24) and diabetes (4) are also recognized confounders. To identify CVD we used an inclusive measure of coronary heart disease (including abnormal resting ECG, angina, and myocardial infarction). Cases of diabetes were obtained from recall of a physician's diagnosis.

\section{STATISTICAL ANALYSIS}

The association between blood pressure and cognitive function was estimated using both multiple logistic regression analyses and multiple linear regressions. For the logistic regression poor cognitive function was indicated by being in the worst quintile (13). The blood pressure categories of low (the reference group), medium and high were used to estimate risk of poor cognitive function. We examined these relationships using baseline (prospective analysis) and current (cross-sectional analysis) blood pressure. Continuous measures of blood pressure and cognitive function were used in the multiple linear regression analysis. All analyses were carried out separately for men and women to explore a possible effect modification by gender. 


\section{RESULTS}

10,308 individuals were examined at baseline (Phase 1, 1985-1988). A total of 355 participants died between Phases 1 and 5 (mean follow-up of 11 years) and 69 individuals (76.8\% men, 23.2\% women) with a stroke diagnosis were excluded from the analyses. At Phase 5 (19971999) 6552 participants attended the clinical screening examination, only 5838 (4158 men \& 1680 women) of these took the cognitive tests. Missing data were more common among the older $(\mathrm{p}<0.001)$ and the lower grade individuals $(\mathrm{p}<0.02)$. Table 1 presents descriptive data on the participants included in the analyses. The average age for men at baseline was 43.93 and that for women was 44.42 years (Table 1). Table 1 also shows a greater concentration of women with low education.

Table 2 shows the prospective and cross-sectional relationship, adjusted for covariates, between poor cognitive function in midlife and blood pressure in men. The prospective analyses show an association between SBP and phonemic fluency (OR, 1.29; 95\% CI, 1.01-1.68), and that between DBP and semantic fluency (OR, 1.31; 95\% CI, 1.01-1.73). The cross-sectional associations were more extensive, with high level of SBP significantly associated with AH 4-I (OR, 1.52; 95\% CI, 1.17-1.97) and medium levels of DBP with memory (OR, 1.32; 95\% CI, 1.08-1.63), AH 4-I (OR, 1.29; 95\% CI, 1.05-1.58), and semantic fluency (OR, 1.52; 95\% CI, $1.26-1.82)$.

The associations between blood pressure and poor cognitive performance in women were more extensive (Table 3). Elevated systolic blood pressure prospectively predicted poor performance on all the cognitive outcomes examined here. A similar trend was observed for the prospective effects of DBP on AH 4-I (OR, 1.85; 95\% CI, 1.10-3.11) and Mill Hill (OR, 1.49; 95\% CI, 1.02-2.18). The cross-sectional analysis (Table 3) revealed high SBP to have an 
association with poor performance on the AH 4-I (OR, 1.65; 95\% CI, 1.07-2.54) and semantic fluency (OR, 1.97; 95\% CI, 1.29-3.03).

Finally, Table 4 presents results with all cognitive tests and both blood pressure measures treated as continuous measures rather than categorized into groups. These results are reported using standardized regression coefficients, calculated from standardized data and reflect the impact on the outcome variable of a change of 1 standard deviation in the predictor variable. For example, in the prospective analysis (Table 4), an increase of one standard deviation in SBP in women is associated with a decrease of .05 of a standard deviation in AH 4-I. The advantage of the standardized regression coefficient is that it allows assessment of the relative importance of predictor variables to be made across different measures of cognitive function. Table 4 shows blood pressure to be more significantly related to cognitive ability among women, in both prospective and cross-sectional analyses. The associations in men were statistically significant only in the cross-sectional analyses, and SBP was associated with more cognitive function outcomes.

\section{DISCUSSION}

In our cohort of middle-aged men and women, there was a small but significant inverse relationship between blood pressure and cognitive ability. Elevated blood pressure, both systolic and diastolic, was associated with poor cognitive performance. The effect of blood pressure on cognition was stronger among women, and was stronger for some measures of cognitive ability than others. Associations between the two were seen when using baseline blood pressure and blood pressure measured at the time of the cognitive tests. Confounding factors of age, educational level, occupational position, smoking, alcohol consumption, use of antihypertensive 
medication, diagnoses of diabetes and cardiovascular disease were controlled in the analyses; and individuals diagnosed with stroke were excluded.

The association between blood pressure and cognition has been extensively investigated in the Framingham study $(2,3,4,20,22)$. Initial reports of no cross-sectional association were revised when BP over 26 years of longitudinal observation showed an association with poor cognitive ability $(2,3,22)$. Elias and colleagues concluded that chronic and cumulative processes related to hypertension were causally related to modest declines in cognitive functioning in older adults (2). Other longitudinal studies like the Honolulu and Uppsala (5) studies have also found elevated blood pressure in midlife to be related to dementia and cognitive impairment in laterlife.

It has remained unclear if the relationship between blood pressure and cognition extended to younger, healthier cohorts. This is important because it informs the debate on whether the link between blood pressure and cognitive impairment is causal; and if so, whether subtle neuropsychological changes have already occurred by middle age. Our results show elevated levels of both systolic and diastolic blood pressure to be significantly related to cognitive ability in middle age, independently of the covariates examined. In fact, a recent paper reports the association between elevated blood pressure and poor cognition, specified in that study as performance below 1.5 SD below the mean, to be stronger in the 20-40 age group when compared to the 40-60 age group (14). Poor cognitive performance in early adulthood or in middle age is clinically relevant as it is a marker for poor cognitive reserve. Individual differences in brain reserve capacity are a major factor in explaining threshold differences in the onset of clinical symptoms of dementia in older adults (25). Age-related neuronal attrition is likely to be clinically and symptomatically evident much earlier in individuals with impaired 
cognition in middle age. Evidence also suggests that individuals with mild cognitive impairment progress to clinically diagnosed dementia at an accelerated rate (26-28).

Previous work has demonstrated memory $(2,3,11,29)$, attention $(1,2,8,30)$, and verbal fluency $(2,31)$ to be vulnerable to elevated levels of blood pressure. The specificity of these associations has remained somewhat unclear as a large proportion of the research in this domain has examined this association in the elderly with the use of global tests of dementia like the Mini mental State Examination (5,7,9,32-36) that do not allow different components of cognitive ability to be examined. Our analysis shows blood pressure to be related to verbal fluency, AH 4-I, and memory. Verbal fluency (both phonemic and semantic) and the AH 4-I are measures of executive function or "meta" cognitive ability as it integrates other cognitive processes like memory, attention and speed of information processing (37-39). Studies on dementia clearly show verbal fluency to be one of the affected neuropsychological domains (37-44). Our results suggest that hypertension has an adverse effect on executive or "meta" cognitive abilities, implicating more basic processes like attention, memory and speed of information processing.

Most of the research evidence on the association between hypertension and dementia has been on systolic blood pressure. In younger age groups DBP rather than SBP predicts CHD risk $(45,46,47,48)$ and it is unknown if this could be also the case for cognitive function. Our results show both systolic and diastolic pressure to be important for cognition in the prospective and the cross-sectional analyses. In our study, participants were on average 44.07 years old ( $\mathrm{SD}=5.99)$ when blood pressure was assessed for the prospective analysis and 55.57 years old $(\mathrm{SD}=5.99)$ for the cross-sectional analysis. Among the individuals with high SBP at Phase 5, 32.6\% had high, $55.2 \%$ had medium and $12.2 \%$ had low SBP at Phase 1. Similarly, among individuals with high DBP at Phase 5, 25.7\% had high, 46.2\% had medium and 28.1\% had low DBP at Phase 1 . This suggests that the prospective and cross-sectional effects are not being driven by the same 
individuals and that hypertension has both prospective and concurrent associations with cognitive function.

Most of the relevant research in this area has either been carried out on men only samples $(1,5,7,11,49)$ or the variable gender is treated as a covariate and no difference between men and women reported $(2,9,31,32)$. Our results, particularly in analysis using the entire range of blood pressure and cognitive outcomes, show associations to be much stronger in women. This is unlikely to be a result of confounding by socioeconomic factors as they have been controlled for in the analyses and the stronger effects in women are not confined to aspects of cognition most influenced by social factors, the Mill Hill. Further research is required to assess the significance of this finding, especially as research shows the link between vascular pathology and cognitive impairment to be particularly acute in women amongst the very old (50).

The mechanisms linking elevated blood pressure and poor cognition are thought to involve subtle disturbances in cerebral perfusion which are then thought to have an adverse effect on brain cell metabolism $(2,3,11,30)$. Research shows cerebral oxygen metabolism to be diminished among hypertensives, with ventricular enlargement and white matter lesions also more prevalent (51-54). MRI studies have linked hypertension to brain atrophy (55). It is likely that subclinical changes in brain morphology underlie the association between hypertension and cognitive function. Hypertension appears to be related to a spectrum of brain injury that is clinically asymptomatic but impacts cognitive ability. Brain reserve theory would suggest that brain tissue or neuronal loss has to reach a certain threshold before clinical symptoms of impairment become apparent $(25,56)$. However, this does not rule out changes in the structure of the brain or poor cognitive performance. The effect of vascular disorders have been statistically adjusted in the analyses reported here. However, these diseases do not fully reflect sub-clinical atherosclerosis and small-vessel disease in the brain, which may be a stronger intermediate factor. 
Further research, perhaps with neuroimaging data, is required to elaborate the precise mechanisms linking hypertension to cognitive impairment.

There are obvious caveats to the conclusions drawn in this study. First, sample attrition in most cohorts, including Whitehall II, is more common among older and poorer individuals. However, it is unlikely that the relationship between blood pressure and cognition is different in different groups. Second, the conclusions drawn here apply to poor cognitive function and not cognitive decline. Further waves of data collection will allow us to examine whether the agerelated decline in cognitive function is different for hypertensives.

Public health interest in the association between vascular factors, hypertension in particular, and dementia is driven by the fact that it is a treatable risk factor. Our results have public health significance as elevated levels of blood pressure are found to be related to poor cognitive performance even in a group with a low proportion of hypertensives. Furthermore, the associations are more obvious in women when measures of both blood pressure and cognitive function are treated as being continuously distributed rather than categorized. This suggests that adverse effects of elevated blood pressure are not restricted to the high blood pressure category ( $\mathrm{SBP} \geq 140$ or $\mathrm{DBP} \geq 90$ ). In conclusion, these findings suggest that comprehensive cognitive testing in younger age groups may provide important insights into the association between hypertension and impaired cognitive function. 


\section{Acknowledgements}

AS-M is supported by a 'Chair of excellence' award from the French Ministry of Research. The Whitehall II study has been supported by grants from the Medical Research Council; British Heart Foundation; Health and Safety Executive; Department of Health; National Heart Lung and Blood Institute (HL36310), US, NIH: National Institute on Aging (AG13196), US, NIH; Agency for Health Care Policy Research (HS06516); and the John D and Catherine T MacArthur Foundation Research Networks on Successful Midlife Development and Socio-economic Status and Health. MM is supported by an MRC Research Professorship.

We also thank all participating civil service departments and their welfare, personnel, and establishment officers; the Occupational Health and Safety Agency; the Council of Civil Service Unions; all participating civil servants in the Whitehall II study; and all members of the Whitehall II study team. 


\section{References}

1. Boller F, Vrtunski PB, Mack JL, Kim Y. Neuropsychological correlates of hypertension. Arch Neurol 1977; 34:701-705.

2. Elias MF, Wolf PA, D'Agostino RB, Cobb J, White LR. Untreated blood pressure level is inversely related to cognitive functioning: the Framingham Study. Am J Epidemiol 1993; $138: 353-364$.

3. Elias MF, D'Agostino RB, Elias PK, Wolf PA. Blood pressure, hypertension, and age as risk factors for poor cognitive performance. Exp Aging Res 1995; 21:393-417.

4. Elias PK, Elias MF, D'Agostino RB, Cupples LA, Wilson PW, Silbershatz H, Wolf PA. NIDDM and blood pressure as risk factors for poor cognitive performance. The Framingham Study. Diabetes Care 1997; 20:1388-1395.

5. Kilander L, Nyman H, Boberg M, Hansson L, Lithell H. Hypertension is related to cognitive impairment: a 20-year follow-up of 999 men. Hypertension 1998; 31:780-786.

6. Launer LJ, Masaki K, Petrovich H, Foley D, Havlik RJ. The association between mid-life blood pressure levels and late-life cognitive function: the Honolulu-Asia Aging Study. JAMA 1995; 274:1846-1851.

7. Launer LJ, Ross GW, Petrovich H, Masaki K, Foley D, White LR, Havlik RJ. Midlife blood pressure and dementia: the Honolulu-Asia Aging Study. Neurobiol Aging 2000; 21:49-55.

8. Shapiro AP, Miller RE, King HE, Ginchereau EH, FitzgibbonK. Behavioral consequences of mild hypertension. Hypertension 1982; 4:255-260.

9. Starr, JM, Whalley, LJ, Inch S, Sherring PA. Blood pressure and cognitive function in healthy old people. J Am Geriatr Soc 1993; 41:753-756.

10. Qiu C, von Stauss E, Fastbom J, Winbald B, Fratiglioni L. Low blood pressure and risk of dementia in the Kungsholmen Project. Arch Neurol 2003; 60:223-228. 
11. Swan GE, Carmelli D, Larue A. Systolic blood pressure tracking over 25 to 30 years and cognitive performance in older adults. Stroke 1998; 29: 2334-2340.

12. Sparks DL, Scheff SW, Liu H, Landers TM, Coyne CM, Hunsaker III JC. Increased incidence of neurofibrillary tangles (NFT) in non-demented individuals with hypertension. J Neurol Sci 1995; 131:162-169.

13. Anstey KJ, Luszcz MA, Giles LC, Andrews GR. Demographic, health, cognitive, and sensory variables as predictors of mortality in very old adults. Psychol Aging 2001; 16:3-11.

14. Suhr JA, Stewart JC, France CR. The relationship between blood pressure and cognitive performance in the Third National Health and Nutrition Examination Survey (NHANES III). Psychosom Med 2004; 66:291-297.

15. Marmot MG, Davey Smith G, Stansfeld S, Patel C, North F, Head J, White I, Brunner E, Feeney A. Health inequalities among British civil servants: the Whitehall II study. Lancet $1991 ; 337: 1387-1393$.

16. Chobanian AV, Bakris GL, Black HR, et al., The seventh report of the Joint National Committee on prevention, detection, evaluation, and treatment of high blood pressure. JAMA $2003 ; 289: 2560-2572$.

17. Heim AW. AH 4 group test of general intelligence ASE. Windsor: UK:NFER-Nelson Publishing Company Ltd; 1970.

18. Raven, JC. Guide to using the Mill Hill vocabulary scale with progressive matrices. London: HK Lewis; 1965.

19. Borkowski JG, Benton AL, Spreen O Word fluency and brain damage. Neuropsychologica $1967 ; 5: 135-140$. 
20. Farmer, ME, Kittner, SJ, Abbott, RD et al. Longitudinally measured blood pressure, antihypertensive medication use, and cognitive performance: the Framingham study. J Clin Epidemiol 1990; 43:475-480.

21. Elias MF, Robbins MA, Schultz NR, Pierce TW. Is blood pressure an important variable in research on aging and neuropsychological test performance. J Gerontol 1990; 45:128-135.

22. Elias MF, D’Agostino RB, Elias PK, Wolf PA. Neuropsychological test performance, cognitive functioning, blood pressure, and age: the Framingham Heart Study. Exp Aging Res $1995 ; 21: 369-391$.

23. Waldstein SR, Jennings JR, Ryna CM, Muldoon MF, Shapiro AP, Polefrone JM, Fazzari TV, Manuck SB. Hypertension and neuro psychological performance in men: interactive effects of age. Health Psychol 1996; 15:102-109.

24. Zhu L, Vittanen M, Guo Z, Winbald B, Fratiglioni L. Blood pressure reduction, cardiovascular diseases, and cognitive decline in the Mini-Mental State Examination in a community population of normal very old people: a three-year follow-up. J Clin Epidemiol 1998; 51: 385-391.

25. Satz P. Brain reserve capacity on symptom onset after brain injury: A formulation and review of evidence for threshold theory. Neuropsychol 1993; 7:273-295.

26. Chertkow H. Mild cognitive impairment. Current Upinion in Neurology 2002; 15: 401-407.

27. Morris JC, Storandt M, Miller P, McKeel DW, Price JL, Rubin EH, Berg L. Mild cognitive impairment represents early-stage Alzheimer's disease. Arch Neurol 2001; 58:397-405.

28. Petersen RC, Doody R, Kurz A, Mohs RC, Morris JC, Rabins PV, Ritchie K, Rossor M, Thal L, Winbald L. Current concepts in mild cognitive impairment. Arch Neurol 2001; 58:19851992. 
29. Waldstein SR, Ryan CM, Manuck SB. Learning and memory function in men with untreated blood pressure elevation. J Consult Clin Psychol 1991; 59:513-517.

30. Waldstein SR. Health effects on cognitive aging. In: Stern PC, Cartensen LL, Eds. The Aging mind: opportunities in cognitive research. The National Academy of Sciences; 2000:189-217.

31. de Moraes SA, Szklo M, Knopman D, Sato R. The relationship between temporal changes in blood pressure and changes in cognitive function: atherosclerosis risk in communities (ARIC) study. Prev Med 2002; 35:258-263.

32. Glynn RJ, Beckett LA, Hebert LE, Morris MC, Scherr PA, Evans DA. Current and remote blood pressure and cognitive decline. JAMA 1999; 281:438-445.

33. Budge MM, de Jager, Hogervorst E, Smith AD. Total plasma homocysteine, age, systolic blood pressure, and cognitive performance in older people. J Am Geriatr Soc 2002; 50:20142018.

34. Morris MC, Scherr PA, Hebert LE, Glynn RJ, Bennett DA, Evans DA. Association of incident Alzheimer Disease and blood pressure measured from 13 years before to 2 years after diagnosis in a large community study. Arch Neurol 2001; 58:1640-1646.

35. Murray MD, Lane KA, Gao S, Evans RM, Unverzagt FW, Hall KS, Hendrie H. Preservation of cognitive function with antihypertensive medication. Arch Intern Med 2002; 162:20902096.

36. Tzourio C, Andersen C, Chapman N, Woodward M, Neal B, MacMohan S, Chalmers J. Effects of blood pressure lowering with perindopril and indapamide therapy on dementia and cognitive decline in patients with cerebrovascular disease. Arch Intern Med 2003; 163:10691073. 
37. Benito-Cuadrado MM, Esteba-Castillo S, Bohm P, Cejudo-Bolivar J, Pena-Casanova J. Semantic verbal fluency of animals: a normative and predictive study in the Spanish population. J Clin Exp Neuropsychol 2002; 24:1117-1122.

38. Bryan J, Luszcz MA. Measurement of executive function: considerations for detecting adult age differences. J Clin Exp Neuropsychol 2000; 22:40-55.

39. Chertkow H, Bub D. Semantic memory loss in dementia of Alzheimer's type. What do various measures measure? Brain 1990; 113:397-417.

40. Brady CB, Spiro A, McGlinchey-Berroth R., Milberg W., Gaziano JM. Stroke risk predicts verbal fluency decline in health older men. J Gerontol B Psychol Sci Soc Sci 2001; 56:P340P346.

41. Fahlander K, Wahlin A, Almkvist O, \& Backman L. Cognitive functioning in Alzheimer's disease and vascular dementia: further evidence for similar patterns of deficits. J Clin Exp Neuropsychol 2002; 24:734-744.

42. Jacobs DM, Marder K, Cote LJ, Sano M, Stern Y, Mayeux R. Neuropsychological characteristics of preclinical dementia in Parkinson's disease. Neurology 1995; 45:16911696.

43. Monsch AU, Bondi MW, Butters N, Salmon DP, Katzman R, Thal LJ. Comparisons of verbal fluency tasks in the detection of dementia of the Alzheimer type. Arch Neurol 1992; 49:12531258.

44. Starkstein SE, Sabe L, Vazquez S, Teson A, Petracca G, Chemerinski E, Di Lorenzo G, Leiguarda R. Neuropsychological, psychiatric, and cerebral blood flow findings in vascular dementia and Alzheimer's disease. Stroke 1996; 27:408-414. 
45. Franklin SS, Larson MG, Khan SA, Wong ND, Leip EP, Kannel WB, Levy D. Does the relation of blood pressure to coronary heart disease risk change with aging? The Framingham Heart Study. Circulation 2001; 103:1245-1249.

46. Kannel WB, Gordon T, Schwartz MJ. Systolic versus diastolic blood pressure and the risk of coronary heart disease. Am J Cardiol 1971; 27:335-346.

47. Lichtenstein MJ, Shipley MJ, Rose G. Systolic and diastolic blood pressures as predictors of coronary heart disease mortality in the Whitehall study. BMJ 1985; 291:243-245.

48. Trevdal A. Systolic and diastolic blood pressures as predictors of coronary heart disease in middle aged Norwegian men. BMJ 1987; 294:671-673.

49. Carmelli D, Swan GE, Reed T, Wolf PA, Miller BL, DeCarli C. Midlife cardiovascular risk factors and brain morphology in identical older male twins. Neurology 1999; 52:1119-1124.

50. Aronson MK, Ooi WL, Morgenstern H. Women, myocardial infarction, and dementia in the very old. Neurology 1990; 40:1102-6.

51. Fujishima M, Ibayashi S, Fujii K, Mori S. Cerebral blood flow and brain function in hypertension. Hypertens Res 1995; 18:111-117.

52. Breteler MMB, van Swieten JC, Bots ML, Grobbee DE, Claus JJ, van den Hout JHW, van Harskamp F, Tanghe HLJ, de Jong PTVM, van Gijn J, Hofman A. Cerebral white matter lesions, vascular risk factors, and cognitive function in a population-based study: the Rotterdam Study. Neurology 1994; 44:1246-1252.

53. DeCarli C, Murphy DGM, Tranh M, Grady CL, Haxby JV, Gillette JA, Salerno JA, Gonzales-Aviles A, Horowitz B, Rapoport SI. The effect of white matter hyperintensity volume on brain structure, cognitive performance, and cerebral metabolism of glucose in 51 healthy adults. Neurology 1995; 45:2077-2084. 
54. Schmidt R, Fazekas F, Koch M, Kapellar P, Augustin M, Offenbacher H, Fazekas G, Lechner H. Magnetic resonance imaging cerebral abnormalities and neuropsychologic test performance in elderly hypertensive subjects: a case-control study. Arch Neurol 1995; 52:905-910.

55. Salerno JA, Murphy DGM, Horwitz B, DeCarli C, Haxby JV, Rapoport SI, Schapiro MB. Brain atrophy in hypertension: a volumetric magnetic resonance imaging study. Hypertension $1992 ; 20: 340-348$.

56. Katzman R. Education and the prevalence of dementia and Alzheimer's disease. Neurology $1993 ; 43: 13-20$. 
TABLE 1. Characteristics of participants in Whitehall II.

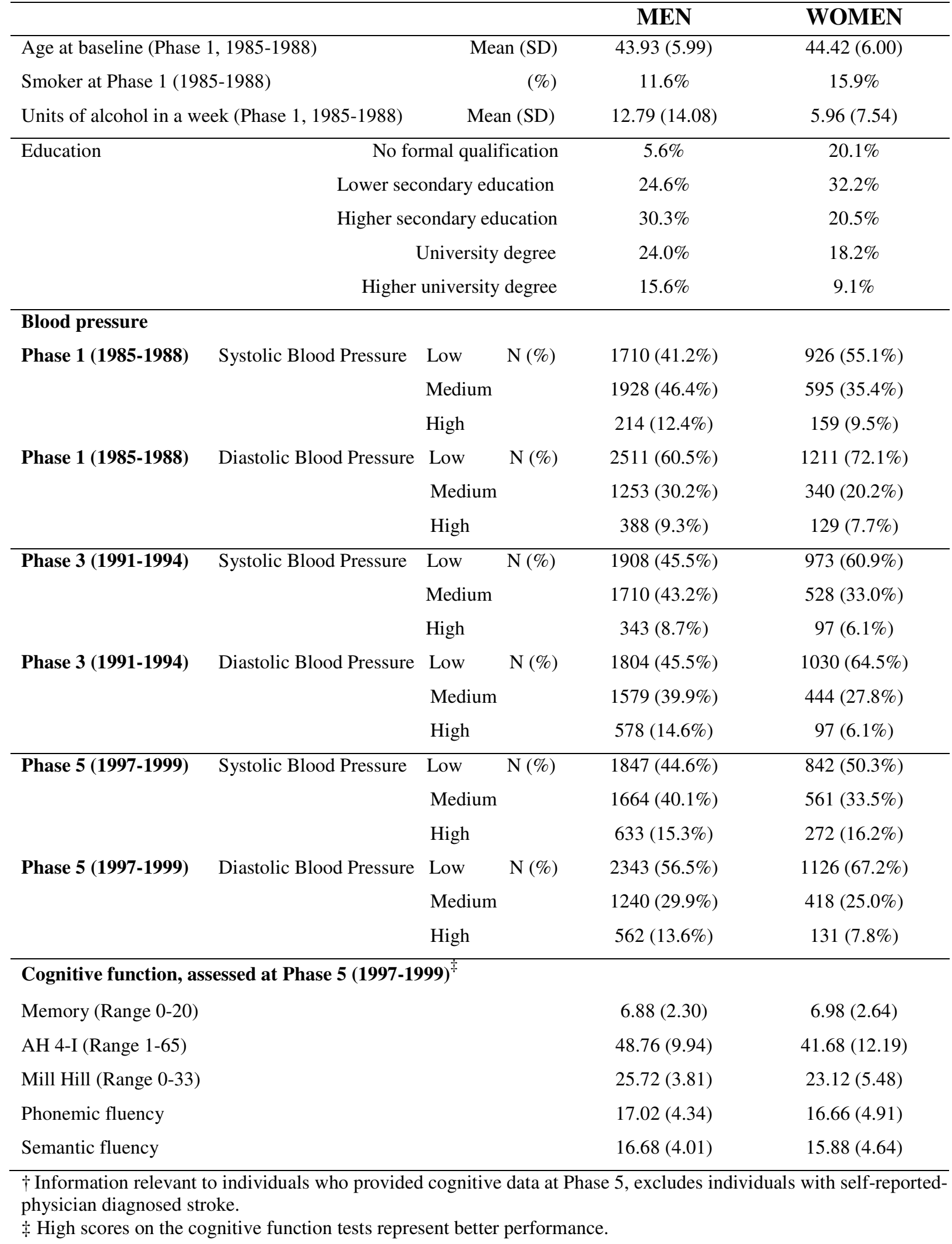


TABLE 2. Prospective and cross-sectional association between blood pressure and being in the worst quintile of cognitive function in men. $\uparrow \neq$

\begin{tabular}{|c|c|c|c|c|c|}
\hline & Memory & AH 4-I & Mill Hill & $\begin{array}{c}\text { Phonemic } \\
\text { fluency }\end{array}$ & $\begin{array}{c}\text { Semantic } \\
\text { fluency }\end{array}$ \\
\hline & OR (95\% CI) & OR (95\% CI) & OR (95\% CI) & OR (95\% CI) & OR (95\% CI) \\
\hline \multicolumn{6}{|c|}{ Prospective analysis (Blood pressure assessed at Phase 1, 1985-1988 and cognition at Phase 5, 1997-1999) } \\
\hline \multicolumn{6}{|c|}{ Systolic Blood Pressure } \\
\hline Low $(<120)$ & 1 & 1 & 1 & 1 & 1 \\
\hline Medium (120-139) & $0.92(0.76-1.13)$ & $1.01(0.83-1.23)$ & $0.97(0.80-1.16)$ & $1.05(0.87-1.25)$ & $1.12(0.94-1.34)$ \\
\hline $\operatorname{High}(\geq 140)$ & $1.06(0.79-1.43)$ & $1.13(0.84-1.52)$ & $1.06(0.80-1.40)$ & $1.29(1.01-1.68)$ & $1.07(0.82-1.41)$ \\
\hline \multicolumn{6}{|c|}{ Diastolic Blood Pressure } \\
\hline Low $(<80)$ & 1 & 1 & 1 & 1 & 1 \\
\hline Medium (80-89) & $1.02(0.83-1.25)$ & $1.01(0.83-1.24)$ & $1.15(0.95-1.39)$ & $1.08(0.90-1.30)$ & $1.05(0.87-1.27)$ \\
\hline High $(\geq 90)$ & $1.29(0.95-1.75)$ & $0.74(0.53-1.04)$ & $0.89(0.66-1.22)$ & $1.22(0.92-1.61)$ & $1.31(1.01-1.73)$ \\
\hline
\end{tabular}

Cross-sectional analysis (Both blood pressure and cognition assessed at Phase 5, 1997-1999)

Systolic Blood Pressure

Medium (120-139)

1

High $(\geq 140)$

$1.03(0.84-1.27)$

1

1

$1.11(0.91-1.37) \quad 1.12(0.93-1.35) \quad 1.11(0.92-1.33) \quad 1.16(0.97-1.39)$

Diastolic Blood Pressure

$\begin{array}{llllll}\text { Low }(<80) & 1 & 1 & 1 & 1 & 1\end{array}$

Medium (80-89) $\quad \mathbf{1 . 3 2}(\mathbf{1 . 0 8}-1.63) \quad \mathbf{1 . 2 9}(\mathbf{1 . 0 5 - 1 . 5 8 )} \quad 1.20(0.99-1.45) \quad 1.17(0.98-1.41) \quad \mathbf{1 . 5 2}(\mathbf{1 . 2 6 - 1 . 8 2})$

High $(\geq 90) \quad 1.15(0.87-1.53) \quad 1.03(0.78-1.36) \quad 1.06(0.82-1.37) \quad 0.98(0.76-1.26) \quad 1.07(0.83-1.39)$

\footnotetext{
${ }^{7}$ For each test poor cognitive function was indicated by being in the worst quintile. Odds-ratios significant at $\mathrm{p}<0.05$ are in bold.

$\doteqdot$ Adjusted for age, occupational position, education, alcohol consumption, smoking, use of antihypertensive medication, diagnosis of diabetes and CVD; excluding individuals with stroke.
} 
TABLE 3. Prospective and cross-sectional association between blood pressure and being in the worst quintile of cognitive function in women. $\dagger+$

\begin{tabular}{|c|c|c|c|c|c|}
\hline & Memory & AH 4-I & Mill Hill & $\begin{array}{c}\text { Phonemic } \\
\text { fluency }\end{array}$ & $\begin{array}{c}\text { Semantic } \\
\text { fluency }\end{array}$ \\
\hline & OR $(95 \% \mathrm{CI})$ & OR $(95 \% \mathrm{CI})$ & OR $(95 \%$ CI $)$ & OR $(95 \%$ CI $)$ & OR $(95 \% \mathrm{CI})$ \\
\hline \multicolumn{6}{|c|}{ Prospective analysis (Blood pressure assessed at Phase 1, 1985-1988 and cognition at Phase 5, 1997-1999) } \\
\hline \multicolumn{6}{|c|}{ Systolic Blood Pressure } \\
\hline Low $(<120)$ & 1 & 1 & 1 & 1 & 1 \\
\hline Medium (120-139) & $1.48(1.04-1.93)$ & $1.35(0.97-1.89)$ & $0.89(0.63-1.26)$ & $1.42(1.04-1.93)$ & $1.13(0.81-1.59)$ \\
\hline High $(\geq 140)$ & $1.28(0.78-2.10)$ & $1.53(0.90-2.58)$ & $2.03(1.19-3.46)$ & $1.66(1.03-2.67)$ & $1.89(1.15-3.11)$ \\
\hline \multicolumn{6}{|c|}{ Diastolic Blood Pressure } \\
\hline Low $(<80)$ & 1 & 1 & 1 & 1 & 1 \\
\hline Medium (80-89) & $1.15(0.81-1.63)$ & $1.30(0.89-1.89)$ & $1.49(1.02-2.18)$ & $1.24(0.88-1.76)$ & $1.06(0.72-1.54)$ \\
\hline High $(\geq 90)$ & $1.15(0.69-1.93)$ & $1.85(1.10-3.11)$ & $1.55(0.90-2.67)$ & $1.45(0.88-2.38)$ & $1.30(0.76-2.21)$ \\
\hline
\end{tabular}

Cross-sectional analysis (Both blood pressure and cognition assessed at Phase 5, 1997-1999)

Systolic Blood Pressure

$\begin{array}{llllll}\text { Low }(<120) & 1 & 1 & 1 & 1 & 1 \\ \text { Medium (120-139) } & 1.23(0.88-1.70) & 1.35(0.95-1.92) & 1.13(0.79-1.61) & 1.15(0.82-1.60) & 1.31(0.91-1.88) \\ \text { High }(\geq 140) & 1.24(0.82-1.86) & \mathbf{1 . 6 5}(\mathbf{1 . 0 7 - 2 . 5 4}) & 1.18(0.75-1.84) & 1.44(0.97-2.16) & \mathbf{1 . 9 7}(\mathbf{1 . 2 9}-3.03)\end{array}$

Diastolic Blood Pressure

$\begin{array}{llllll}\text { Low }(<80) & 1 & 1 & 1 & 1 & 1\end{array}$

Medium (80-89) $\quad 1.31(0.95-1.83) \quad 1.23(0.86-1.76) \quad 0.95(0.65-1.38) \quad 1.13(0.81-1.58) \quad \mathbf{1 . 5 0}(\mathbf{1 . 0 5 - 2 . 1 3})$

High ( $\geq 90) \quad 1.39(0.84-2.30) \quad 1.50(0.87-2.59) \quad 1.44(0.81-2.43) \quad 0.94(0.54-1.62) \quad 1.22(0.69-2.13)$

${ }^{\dagger}$ For each test poor cognitive function was indicated by being in the worst quintile. Odds-ratios significant at $\mathrm{p}<0.05$ are in bold.

Adjusted for age, occupational position, education, alcohol consumption, smoking, diagnosis of diabetes and CVD; excluding individuals with stroke. 
TABLE 4. Linear regression results showing the association between blood pressure and cognitive function. + \$

\begin{tabular}{|c|c|c|c|c|}
\hline & \multicolumn{2}{|c|}{ MEN } & \multicolumn{2}{|c|}{ WOMEN } \\
\hline & SBP & DBP & SBP & DBP \\
\hline \multicolumn{5}{|c|}{$\begin{array}{l}\text { Prospective analysis (Blood pressure and assessed at Phase 1, 1985-1988 and cognition at Phase 5, } 1997 \text { - } \\
\text { 1999) }\end{array}$} \\
\hline Memory & -.02 & -.02 & -.04 & -.05 \\
\hline AH 4-I & -.01 & .01 & $-.05 * *$ & -.04 \\
\hline Mill Hill & .00 & -.01 & $-.04 *$ & $-.06 * *$ \\
\hline Phonemic fluency & -.01 & -.02 & $-.08 * *$ & $-.06 * *$ \\
\hline Semantic fluency & -.01 & -.01 & $-.06 * *$ & $-.08 * * *$ \\
\hline \multicolumn{5}{|c|}{ Cross-sectional analysis (Both blood pressure and cognition assessed at Phase 5, 1997-1999) } \\
\hline Memory & -.02 & $-.05^{* *}$ & -.03 & $-.06^{*}$ \\
\hline AH 4-I & $-.03 *$ & -.01 & $-.06 * *$ & $-.04 *$ \\
\hline Mill Hill & $-.04 * *$ & -.02 & -.03 & $-.05^{*}$ \\
\hline Phonemic fluency & $-.03 *$ & -.02 & $-.05^{*}$ & -.04 \\
\hline Semantic fluency & $-.04 * *$ & $-.03 *$ & -.04 & -.04 \\
\hline
\end{tabular}

$* \mathrm{p}<0.05 ; * * \mathrm{p}<0.01 ; * * * \mathrm{p}<.001$

Association expressed as a beta, the standardized regression coefficient; High scores on all tests of cognitive function denote better performance.

$\doteqdot$ Adjusted for age, occupational position, education, alcohol consumption, smoking, use of antihypertensive medication, diagnosis of diabetes and CVD; excluding individuals with stroke. 